\title{
Illuminations: Brian Cherney at Seventy-Five
}

\author{
by Robin Elliott, University of Toronto
}

The Schulich School of Music at McGill University hosted a symposium on October 27th and 28th, 2017 to celebrate the life and career of the composer Brian Cherney on the occasion of his 75th birthday. Supported by a Social Sciences and Humanities Research Council of Canada Connections Grant, the symposium featured four lecture sessions, three concerts, and a curated display of Cherney's scores in the Marvin Duchow Music Library. The formal events were punctuated by informal receptions that were enlivened by animated conversations among the hundred or so people attending the events, who came from across Canada and the United States. The conference director, Aiyun Huang, is a percussionist and was also Cherney's colleague at McGill up until her recent appointment to the University of Toronto. She was assisted by three young composers who studied with Cherney at McGill and are now all based in New York City: Taylor Brook, Zosha Di Castri, and Matthew Ricketts. An attractive 44-page booklet provides detailed information about the symposium events, the presenters, and the performers; it can be downloaded in PDF format from the McGill website at https://www.mcgill.ca/cherney75/.

The ten papers touched on many aspects of Cherney's music, ranging from overviews of topoi that recur frequently in his oeuvre (e.g. stillness, time, quotation and allusion, spirituality, "ascending music" [Cherney's phrase]), to detailed explorations of compositional techniques as evidenced in specific works (e.g. symmetrical pitch, harmonic, and structural devices; use of the Fibonacci series; modal, chromatic and octatonic pitch collections). Other papers touched upon the commissioning of the String Trio of 1976 (which Cherney has identified as a particularly important milestone in his development as a composer) and his work as a scholar in two areas, music in Weimar Germany and Canadian music. In an entertaining talk titled "How I Might Have Become a Composer," Cherney reflected on the path that took him from piano lessons at age 5 in his native Peterborough, to the decision to become a composer, tracing steps along an arc that led towards increasing confidence in the need for his music to "disturb the universe," as he put it (quoting T.S. Eliot). Further insight into his career and music was provided by a wideranging interview between Cherney and his McGill composition colleague Chris Harman. 
Cherney's finely honed sense of humour was evident from the library exhibition, titled "The Score's the Thing: Humour and the Absurd in the Music of Brian Cherney" (on display until December 2017). Included in the exhibition is the complete score of his comic-strip-like theatrical composition Brahms and the German Spirit (2009), as well as excerpts from four other works and an amusingly self-deprecating autobiographical vignette. The eleven works that were presented in the three concerts extended over Cherney's entire career, with representative works drawn from each decade from the 1970s to the present. About threequarters of Cherney's output of ca. 100 works are for instrumental solo or chamber configurations; the other quarter is split between orchestral and vocal/choral repertoire. All but one of the works that were heard in the superb performances were purely instrumental, ranging from solo viola to a chamber orchestra of 22 musicians. Several of the works discussed in the papers were also heard in live performance, providing a particularly welcome synergy to the symposium. The two days shed much light on Cherney's career and his varied, inventive, and expressive compositions, and offered some well-deserved recognition for this outstanding musician, teacher, and scholar, who clearly inspires a great deal of love, loyalty, and devotion from his many friends, students, and colleagues.

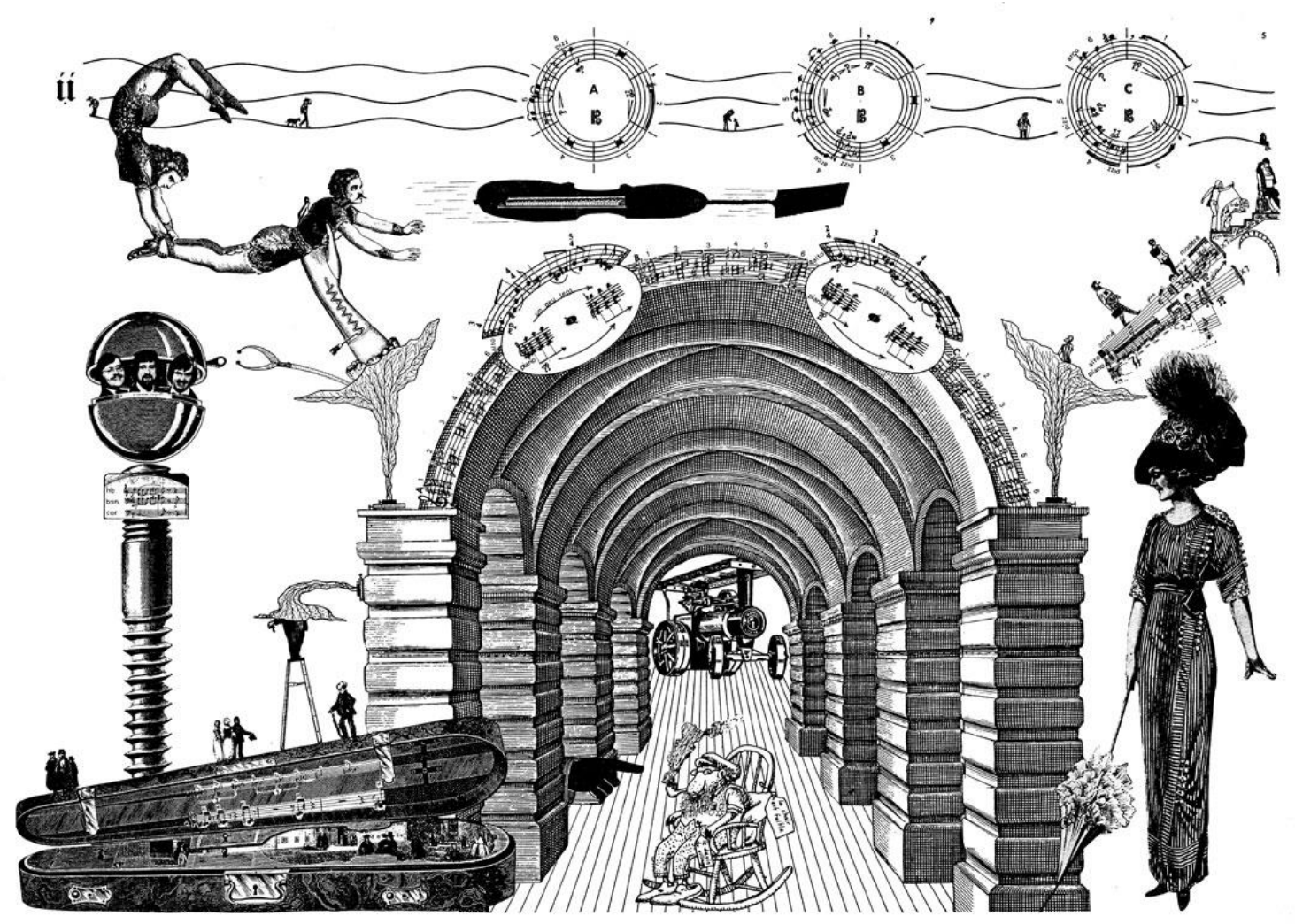

Brian Cherney, Trois pièces desséchées ... en forme de sandwich for viola and piano (1979): second movement; on display in the exhibition The Score's the Thing: Humour and the Absurd in the Music of Brian Cherney, Marvin Duchow Music Library, McGill University, September - December 2017 